\title{
PARASITE LOAD, BODY SIZE, AND AGE OF WILD-CAUGHT MALE FIELD CRICKETS (ORTHOPTERA: GRYLLIDAE): EFFECTS ON SEXUAL SELECTION
}

\author{
MARLENE ZUK' \\ Museum of Zoology, University of Michigan, Ann Arbor, MI 48109
}

\begin{abstract}
Comparison of male field crickets (Gryllus veletis and G. pennsylvanicus) collected either by themselves (solitary) or with one or more females (paired) showed that the paired males were significantly older and significantly less parasitized by gregarines (protozoan gut parasites) than were solitary males. Body size did not differ between the two groups. These results corroborate earlier experimental findings that females are preferentially attracted to older males and suggest that the ability of less parasitized males to produce more spermatophores under laboratory conditions may also be important in the field. Calculation of sexual-selection differentials and gradients for $G$. pennsylvanicus did not reveal any indirect selection on body size and confirmed the strong selection on male age.
\end{abstract}

Received July 14, 1987. Accepted March 18, 1988

Most empirical studies of sexual selection have concentrated on either laboratory or field aspects, but rarely both (Howard, 1978; Partridge, 1980; Bateson, 1982; Price, 1984; Houde, 1987; for exceptions, see Thornhill [1983] and Watt et al. [1986]). The difficulty with observing traits that appear to be important in mate choice in the field without corroborating their importance experimentally is that one can seldom be sure which characters are actually the object of selection. Conversely, in laboratory studies it may be hard to know if traits that affect mate choice under controlled conditions are relevant in the field.

Male field crickets (Gryllidae) signal their availability to females by singing from relatively fixed positions; females approach a particular male and receive one or more spermatophores from him (Alexander, 1961). Previous experimental work on the two species of northern field cricket (Gryllus veletis and $G$. pennsylvanicus) in Michigan demonstrated that male age was significantly correlated with the number of females attracted (Zuk, 1987a). After a female has been attracted to a male, his ability to replace spermatophores relatively quickly was negatively correlated with the level of protozoan gut parasites called gregarines (Zuk, 1987b); because female fecundity and sperm storage are higher with multiple in-

\footnotetext{
1 Present address: Department of Biology, University of New Mexico, Albuquerque, NM 87131.
}

seminations (Sakaluk and Cade, 1980; Simmons, 1986), males that replace spermatophores quickly may have higher mating success than those that do not.

In this paper, I present the results of a comparison of males that have been successful in attracting a female in the field with those that have not. Using a cross-sectional sample, I contrasted male crickets found alone versus those found courting or associating with females, in terms of age since adult molt, gregarine parasite levels, and two body-size measurements to determine whether the characteristics that were important in experiments were relevant under natural conditions.

The relationship between parasite load and mating success was of particular interest as a test of Hamilton and Zuk's (1982) theory of sexual selection, which predicts that male freedom from parasites and disease should be an important criterion in mate choice by females, who thereby gain an increase in fitness for their offspring (Hamilton, 1982; Hamilton and Zuk, 1982). The field experiment mentioned above showing a correlation between the number of females attracted by males and male age did not show a correlation between parasite load and the number of females attracted (Zuk, $1987 a$ ). However, parasites do appear to influence the outcome of interactions between males and females after initial attraction (i.e., during spermatophore transfer); healthier males produce significantly 
more spermatophores than do parasitized males (Zuk, 1987b), and multiple spermatophore transfer is correlated with increased fecundity (Sakaluk and Cade, 1980). Parasites thus appear to be a component of sexual selection in field crickets. Examination of the interaction of age and parasite load in field populations was therefore crucial to understanding the importance of these factors in mate choice.

The data presented here are similar to those of McCauley and Wade (1978) for a population of soldier beetles; their data were used by Arnold and Wade (1984b) in a single episode measurement of sexual selection. I employed Arnold and Wade's (1984a, $1984 b$ ) methods as well as the multivariate approach of Lande and Arnold (1983) to calculate sexual-selection differentials and gradients for $G$. pennsylvanicus. These coefficients reveal the target and direction of selection and allow the comparison of the magnitude of selection on several different traits (Lande and Arnold, 1983; Price, 1984; Price et al., 1984; Grant, 1985). In previous work, body size of males was not related to either of the experimentally determined components of mating success (Zuk, 1987a, $1987 b$ ). I examined the effects of body size on male attractiveness here both to assess its importance in the field and to determine whether any indirect selection on body size due to correlations between other characters was revealed using the methods of Lande and Arnold (1983).

\section{Materials and Methods}

The research reported here was done on and around the property of the University of Michigan Biological Station in northern Michigan, Cheboygan County.

\section{The Study Animals}

Gryllus veletis and G. pennsylvanicus are temporally separated species with nearly identical appearance and behavior. Gryllus veletis overwinter as nymphs, and in northern Michigan, adults are found from late May until late July; $G$. pennsylvanicus overwinter in the egg stage, and adults are found from late July until autumn frosts (Alexander and Meral, 1967; Lloyd and Pace, 1975). In both species, males call from the entrance of burrows, crevices under rocks and boards, and in leaf litter. When a female has been attracted to a male's call or when a male locates a female by searching, he switches to a distinctive courtship song. Copulation, consisting of the transfer of a spermatophore or sperm package from the male to the female, may then follow (Alexander, 1961). The spermatophore remains attached outside the female's body while its contents drain through a tube into the female's genital opening. Females commonly accept several spermatophores from the same or different males (Sakaluk and Cade, 1980).

\section{The Parasites}

Gregarines (class Sporozoa) are gut parasites of many invertebrates, developing from spores ingested by the host (Hyman, 1940; Kudo, 1954). Crickets can be infected at any stage during the life cycle. Spores pass into the host fore- and midgut, where they attach to the epithelial wall and feed on material present in the gut lumen (Kudo, 1954). Damage to the insect host can occur when large numbers of gregarines block passage of food across the gut or when the epithelium is eroded, allowing passage of more pathogenic bacteria and viruses into the host haemocoel (Bucher, 1959). After a highly variable period ranging from several days to several weeks, the matured gregarines, called trophozoites, detach from the gut, mate, and form walled cysts that are passed out with host feces. Cysts sporulate and become infective outside the host. Infections are therefore usually debilitating rather than lethal; in Gryllus, the parasites have been linked to delayed development, decreased longevity, and decreased adult weight under food deprivation (Zuk, 1987c).

\section{Comparison of Paired and Solitary Males}

To compare the characteristics of unmated males found signalling by themselves with those of successful males (found with females), both $G$. veletis and G. pennsylvanicus were collected in fields, along roadsides, and near buildings of the Biological Station. Males were located both by turning over logs, boards, and stones and by localizing individuals using the calling and courtship songs. The two song types are acoustically quite distinct (Alexander, 1961), and al- 
though males do occasionally give the courtship song when a female is not nearby, such males were not included in the analysis. The infrequent cases in which more than one male was discovered with one or more females were also discarded as ambiguous. Finally, no male later found to be less than six days old was included in the analysis, because regular calling does not begin until 3-6 days after the final molt (Cade, 1981).

The two groups therefore consisted of "solitary" males (found by themselves either calling or silent) and "paired" males (heard courting and then located with a female or else found with one or more females in a shelter). All $G$. veletis paired males were with only one female, but some $G$. pennsylvanicus males had multiple females, and the number of females with each male was recorded in this species.

All males from both categories were collected and frozen immediately. The length of the pronotum and total body length were measured to the nearest $0.1 \mathrm{~mm}$. The guts of thawed crickets were dissected to determine gregarine parasite levels. Gregarine loads were ranked in categories instead of making quantitative counts of parasites, because freezing and thawing the crickets occasionally ruptured gregarine membranes, making cell boundaries of individual trophozoites difficult to distinguish. The amount of moisture and digested food in the gut also affected the integrity of the protozoa.

For $G$. veletis, the following six-tiered scale was used to rank infections:

1) none-no cysts or trophozoites present;

2) very light $-1-3$ cysts and/or trophozoites;

3) light-4-10 cysts and/or trophozoites;

4) moderate-11-30 cysts and trophozoites;

5) heavy-31-50 cysts and/or trophozoites;

6) very heavy - more than 50 cysts and trophozoites with gut occluded in places by parasites.

Many of the $G$. pennsylvanicus males were inadvertently thawed and refrozen, further destroying parasite cell membranes, and so a four-tiered classification, with categories 2 and 3 collapsed into a "light" class and with categories 5 and 6 collapsed into a "heavy" class, was employed for this species.

Age since adult molt was determined for all males, using Neville's (1967) technique, which entails counting chitin rings, which are formed in response to photoperiod and which are visible in cross-sections of tibial or other body segments viewed under the phase-contrast microscope. In a study of the accuracy of the technique for Gryllus, I examined the number of rings counted in tibial sections of laboratory-reared individuals for which exact age could be calculated; the correlation of rings with actual age was highly significant $(N=72, r=0.78, P<0.001)$ for individuals up to 30 days of age (Zuk, 1987d). Out of a sample of 108 field-caught crickets, less than $8 \%$ were more than 18 days old (Zuk, 1987d). Both dissection and aging were performed without knowledge of the group to which a particular male belonged.

\section{Estimation of Mating/Attraction Frequency}

Calculation of sexual-selection differentials and gradients requires estimation of the proportion of mated and unmated individuals in the population (Arnold and Wade, $1984 a, 1984 b$ ). Because paired and solitary males were not sampled in proportion to their abundance in the field (solitary males were easier to locate), data on the frequency with which females were attracted to males were obtained from a separate field experiment. The number of females attracted by a male and the proportion of males attracting any females at all were estimated using caged $G$. pennsylvanicus males suspended over pitfall traps in a field of grass, bracken fern, and aspen stumps. The males were field-caught and were collected and distributed in the cages without regard for their body size, calling rate, parasite load, or age.

The pitfalls, consisting of one-gallon metal cans $17 \mathrm{~cm}$ in diameter, were buried flush with the ground two meters apart. Preliminary observations had shown that crickets could not jump or climb out of the cans. Sixteen adult male $G$. pennsylvanicus in individual $10 \times 10 \times 15 \mathrm{~cm}$ screen cages were placed over alternate pitfalls in two rows of 
15 pitfalls each. Caged males were provided with dry cat chow and lettuce during the experiment. The two rows of pitfalls were $125 \mathrm{~m}$ apart. The pitfall traps between caged males served as comparisons and controls for assessing the number of females that fell into the traps without being attracted to singing males; the traps contained lettuce and other matter (such as dead insects) to serve as food for trapped crickets.

Every day during 14-24 August 1985, the crickets that had fallen into the cans were removed, and the number of adult females in each can was recorded. Crickets captured in the pitfalls were removed from the field and not returned.

\section{Measurement of Selection}

A selection differential may be viewed as the difference in the mean value for a quantitative character before and after selection (Arnold and Wade, 1984a). The selection gradient is the partial regression of relative fitness (individual fitness divided by the mean fitness in the population) on the character being measured (Arnold and Wade, $1984 a$ ). The use of selection gradients allows measurement of selection acting on a particular character not confounded by the effects of correlated characters (Lande and Arnold, 1983). Selection differentials and gradients were calculated for $G$. pennsylvanicus only, since attraction frequency was not estimated in $G$. veletis. Paired males were given a fitness score of 1 , and solitary males a fitness score of 0 ; the scores were transformed to relative fitnesses (Arnold and Wade, 1984a, 1984b; Lande and Arnold, 1983).

Directional selection differentials were calculated as the differences between the mean character value for paired males only and the mean pooled character value for paired and solitary males, corrected for relative proportions of each type as determined by the estimate of mating frequency described above. Selection gradients were calculated by multiplying the standardized selection-differential vector by the inverse of the phenotypic variance-covariance matrix (equivalent to the correlation matrix when the data are standardized) of pronotum length, body length, and age (Lande and Arnold, 1983); this gives the same result as a partial regression and was more suitable to the data. Selection on gregarine load was not measured, because, as a categorical ranked variable, it is not suitable for the analysis (Arnold and Wade, 1984a).

\section{RESULTS}

\section{Comparison of Paired and Solitary Males}

In both Gryllus veletis and $G$. pennsylvanicus, paired males were significantly older and significantly less parasitized than solitary males (Table 1). The paired and solitary groups did not differ significantly in mean body length for either species (Table 1). $G$. pennsylvanicus paired males had marginally significantly longer pronotums than did solitary males $(P=0.05$; Table 1$)$. A previous analysis of the relationships among characters in a different set of caged calling males revealed no significant correlations among calling rate, age, and parasite load (Zuk, 1987a).

Of the 47 paired $G$. pennsylvanicus, 34 $(72 \%)$ were found with one female, $10(21 \%)$ with two females, and one male each with three and five females; females were not accurately counted in one case. For $G$. pennsylvanicus males found with at least one female, the number of females a male was found with was not significantly correlated with pronotum length (Spearman rank correlation coefficient $r_{\mathrm{s}}=-0.11$ ), body length $\left(r_{\mathrm{s}}=0.06\right)$, age $\left(r_{\mathrm{s}}=0.16\right)$, or parasite load $\left(r_{\mathrm{s}}=0.07\right)$.

\section{Estimation of Attraction Frequency}

Pitfalls below caged males trapped a total of 86 females, compared to 31 females for the control pitfalls between caged males; this difference is highly significant (Mann-Whitney $U=48, P<0.01$ ). The number of females found in a male's trap on a single day ranged from 0 to 5 . The number and percentage of traps below males that caught females on each of the 11 days are given in Table 2 ; averaging across the sampling period gives a mean attraction frequency of 0.28 . This figure is an overestimate, since it includes a few females that fell into pitfalls without having been attracted to a male. In addition, males continue to sing in the cages and attract multiple females without having to stop to court and mate females as they 
TABLE 1. Characteristics of male G. veletis and G. pennsylvanicus collected in the field, either by themselves (solitary) or with one or more females (paired). Except where specified, all values are means, with standard errors in parentheses. For the gregarine infection levels, $G$. veletis males were graded from 1 (no infection) to 6 (very heavy infection), and $G$. pennsylvanicus males were graded from 1 (no infection) to 4 (very heavy infection).

\begin{tabular}{lcccc}
\hline \hline \multicolumn{1}{c}{ Characteristic } & Solitary males & Paired males & Mann-Whitney $U$ & $P$ \\
\hline G. veletis: & $N=52$ & $N=37$ & & \\
Pronotum length (mm) & $3.05(0.03)$ & $3.00(0.03)$ & 766.0 & 0.09 \\
Body length (mm) & $17.44(0.16)$ & $17.25(0.17)$ & 819.5 & 0.32 \\
Days since adult molt & $16.74(0.64)$ & $18.86(0.70)$ & 551.5 & 0.009 \\
Gregarine infection level & $4.27(0.20)$ & $3.54(0.21)$ & 654.5 & 0.009 \\
G. pennsylvanicus: & $N=56$ & $N=47$ & & \\
Pronotum length (mm) & $2.94(0.02)$ & $3.00(0.04)$ & $1,031.5$ & 0.05 \\
Body length (mm) & $17.39(0.15)$ & $17.72(0.16)$ & $1,074.5$ & 0.11 \\
Days since adult molt & $9.61(0.40)$ & $11.34(0.62)$ & $1,020.5$ & 0.02 \\
Gregarine infection level & $2.92(0.14)$ & $2.51(0.17)$ & 842.5 & 0.04 \\
\hline
\end{tabular}

are encountered. The estimate as used in subsequent calculations therefore gives a more conservative test of the strength of selection, because in reality less than $28 \%$ of all males probably do mate. Selection is stronger, and the coefficients for selection differentials and gradients are larger, when a smaller proportion of the population mate and produce offspring for the next generation; an overestimate of mating frequency will therefore yield smaller, more conservative values for the strength of selection.

\section{Measurement of Selection}

Table 3 shows the correlations among the three traits for which selection coefficients were calculated. Only body length and pronotum length are significantly correlated with each other $(P<0.01)$.

Selection differentials are often more use-

TABLE 2. Number and percentage of caged $G$. pennsylvanicus males with one or more females found in pitfall traps below them, on each of 11 consecutive days ( $N=16$ caged males). The mean percentage of traps with females was $28 \%$.

\begin{tabular}{rc}
\hline \hline Day & Number of traps with females (\%) \\
\hline 1 & $5(31)$ \\
2 & $1(6)$ \\
3 & $5(31)$ \\
4 & $5(31)$ \\
5 & $12(75)$ \\
6 & $6(38)$ \\
7 & $2(13)$ \\
8 & $5(31)$ \\
9 & $2(13)$ \\
10 & $5(31)$ \\
11 & $2(13)$ \\
\hline
\end{tabular}

fully expressed as standardized selection differentials (the selection differential divided by the standard deviation of the character before selection), because standardized values may be compared among populations in different studies (Arnold and Wade, $1984 a, 1984 b)$. Calculation of this standard deviation, however, requires knowledge of the relative proportions of mated and unmated individuals in the population, and paired and solitary individuals were not sampled in proportion to their abundance in the field. The estimates of 0.28 for mated and $1-0.28$ or 0.72 for unmated individuals were used to obtain a weighted variance for calculating the standardized selection differential, according to the formula

$$
\frac{\mathrm{SS}_{\text {paircd }}(0.28)+\mathrm{SS}_{\text {solitary }}(0.72)}{d . f_{\text {paired }}(0.28)+d . f_{\text {solitary }}(0.72)}
$$

where SS and $d . f$. refer to sums of squares and degrees of freedom, respectively, for each group (solitary and paired). Both the sums of squares and the degrees of freedom are weighted by the proportion of the pop-

TABle 3. Pearson product-moment correlations among body length, pronotum length, and age (number of days since adult molt) in a sample of 47 paired and 56 solitary male $G$. pennsylvanicus.

\begin{tabular}{lcc}
\hline \hline & \multicolumn{2}{c}{ Characteristic } \\
\cline { 2 - 3 } Characteristic & Pronotum length & Body length \\
\hline Body length & $0.671^{\mathrm{a}}$ & - \\
Age & -0.045 & 0.045 \\
\hline a $P<0.01$. & &
\end{tabular}


TABle 4. Standardized and unstandardized selection differentials $(s)$ and standardized selection gradients $(\beta)$ for pronotum length, body length, and age (number of days since adult molt) for mated (paired) versus unmated (solitary) male G. pennsylvanicus.

\begin{tabular}{lccc}
\hline \multicolumn{1}{c}{ Characteristic } & $\begin{array}{c}s \text { (unstand- } \\
\text { ardized) }\end{array}$ & $\begin{array}{c}s \text { (stand- } \\
\text { ardized) }\end{array}$ & $\beta$ \\
\hline Pronotum length & 0.04 & 0.212 & $\mathbf{0 . 1 7 5}$ \\
Body length & 0.24 & 0.215 & 0.080 \\
Age & 1.25 & 0.376 & 0.380 \\
\hline
\end{tabular}

ulation estimated to be paired or solitary. Selection coefficients are given in Table 4. It is important to note that standard errors and, therefore, significance levels could not be calculated for the selection gradients because of this unsystematic sampling (Arnold and Wade, 1984a, 1984b); all coefficients must therefore be taken only as estimates.

\section{DISCUSSION}

The results of this field study show that older, less parasitized males are likely to have higher mating success in nature than younger, more infected ones, corroborating previous experimental findings (Zuk, 1987a, $1987 b$ ). Higher mating success in older males has been documented or inferred in several species of birds (Weatherhead, 1984; Alatalo et al., 1986), anuran amphibians (Howard, 1978), and insects (Thornhill and Alcock, 1983; Zeigler and Stewart, 1985). Halliday $(1978,1983)$ proposed that in preferring older males, females are in fact using the only reliable indicator of "genetic quality." Additionally, if deleterious mutations are lethal at various ages past maturity, females choosing older males are selecting from a pool of mates with a lower probability of carrying the detrimental alleles (Manning, 1985).

The discovery that up to five females per day could be encountered by a male cricket assumes particular significance in light of the lower parasite levels found in paired males compared with solitary ones. Heavily parasitized male $G$. veletis and $G$. pennsylvanicus produce fewer spermatophores per unit time than do less parasitized males (Zuk, $1987 \mathrm{~b}$ ), and female field crickets produce more offspring when they receive more than one spermatophore (Sakaluk and Cade, 1980). Simmons (1986) proposed that, by mating repeatedly with high quality males, females dilute sperm from previous matings, thus increasing the number of offspring sired by the most recent male. Females that receive multiple spermatophores from the same male probably stay with that male longer than they would if he had been capable of manufacturing only one spermatophore (Loher and Rence, 1978). Males had two or more females with them in $25 \%$ of all cases of paired Gryllus pennsylvanicus males in this study. Therefore, because males producing multiple spermatophores probably have fewer gregarines, females are expected to be found more frequently with less parasitized males, the result shown in Table 1. If a maximum of five females per day might indeed be encountered by a male in the field, his mating success depends in part on his ability to produce multiple spermatophores in a short time. While speculative, this line of reasoning is also consistent with the finding that parasite load is not a criterion in initial attraction of females to calling males (Zuk, 1987a). Clearly, more research is needed on the length of time females spend with males and on the factors that influence their departure.

The comparison of parasite loads in males with and without mates also provides one of the few tests of Hamilton and Zuk's (1982) hypothesis about the importance of parasites in sexual selection. Other studies have either concentrated on interspecific comparisons (Read, 1987) or found negative results (Borgia, 1986; for an exception, see Kennedy et al. [1987]).

The results of the measurement of selection on age and the two body characters in $G$. pennsylvanicus must be viewed with caution, both because the method for estimating mating frequency was indirect and because the use of separate data sets for estimating mating frequency and for calculating the selection coefficients meant that standard errors could not be obtained. Nonetheless, the use of a weighted variance term still permitted calculation of the coefficients, suggesting that the techniques are potentially useful even when available data are not ideally suited to the original methods. Two interesting implications arise from the analysis performed here.

First, although paired males have longer 
pronotums than solitary males (Table 1), this distinction becomes less apparent when the selection differentials and gradients are calculated, suggesting that pronotum length is not under strong sexual selection, at least in this context. The coefficients for body length are similarly nonsignificant. The use of the Lande and Arnold (1983) method allows the separate measurement of selection on these two correlated characters and is useful here in showing that selection is not, for example, strongly positive on pronotum length but negative on body length, producing a net effect of no differences between the paired and solitary groups of males. Such conflicting forces of selection were noted in Lande and Arnold's (1983) pentatomid bug data, Grant's (1985) study of Darwin's finches, and in Price et al. (1984).

The second result of this analysis is the striking selection on male age (Table 4). The use of age as a "character," being somewhat unorthodox, deserves some discussion, because age itself is obviously not heritable. Traits that may be involved in a response to selection on age include longevity, rapid development, and early development; all have been shown to be heritable in insects (e.g., Dingle, 1983). Selection on any of these characters could result in older available mates. With regard to developmental time, it is interesting to note that adult $G$. pennsylvanicus found to harbor gregarines at eclosion took significantly longer to develop than did uninfected individuals (Zuk, $1987 c$ ). Male age may also be correlated with some unmeasured character that in itself attracts more females. The cue that females respond to when they preferentially approach older males is as yet unknown, although preliminary experiments suggest that the number of pulses, or wingstrokes, per chirp, is positively correlated with age (Zuk, unpubl.). If this trend is confirmed, a selection gradient including the number of pulses should show no direct selection on age.

In conclusion, both of the traits suggested by laboratory and field experiments to be important in sexual selection in $G$. veletis and $G$. pennsylvanicus were also relevant under natural conditions. The finding that solitary males are more parasitized than paired males is consistent with Hamilton and Zuk's (1982) suggestion that parasites play a role in mate choice, albeit not in the manner originally proposed. Body size does not seem to be important at the stage of sexual selection examined in this study, but it may influence other contributors to variation in mating success, such as male aggressive behavior (Dixon and Cade, 1986). Finally, although numerous researchers have predicted female choice for older males (Halliday, 1978, 1983; Thornhill and Alcock, 1983), caution must be used in analyzing the effects of such choice, since age itself is unlikely to be the actual character under selection.

\section{ACKNOWLEDGMENTS}

I thank my committee members, R. D. Alexander, W. H. Cade, P. R. Grant, W. G. Holmes, P. Smouse, and especially W. D. Hamilton, for their help and advice throughout my research. P. Decker gave valuable field assistance, and J. T. Rotenberry provided essential statistical advice. W. H. Cade, B. R. Grant, T. D. Price, T. Walker, T. Burk and an anonymous reviewer made useful comments on an earlier version of the manuscript. My research was supported by Walker-Hinsdale Scholarships from the University of Michigan Museum of Zoology, the Division of Biological Sciences, the Horace H. Rackham School of Graduate Studies, and the University of Michigan Biological Station.

\section{Literature Cited}

Alatalo, R. V., L. Gustafsson, and A. Lundberg. 1986. Do females prefer older males in polygynous bird species? Amer. Natur. 127:241-245.

AlEXANDER, R. D. 1961. Aggressiveness, territoriality and sexual behavior in field crickets (Orthoptera:Gryllidae). Behaviour 17:130-223.

Alexander, R. D., AND G. H. Meral. 1967. Seasonal and daily chirping cycles in the northern spring and fall field crickets, Gryllus veletis and $G$. pennsylvanicus. Ohio J. Sci. 67:200-209.

ARNOLD, S. J., AND M. J. WADE. $1984 a$. On the measurement of natural and sexual selection: Theory. Evolution 38:709-719.

. $1984 \mathrm{~b}$. On the measurement of natural and sexual selection: Applications. Evolution 38:720734.

Bateson, P. P. G. 1982. Preference for cousins in Japanese quail. Nature 295:236-237.

BorgiA, G. 1986. Satin bowerbird parasites: A test of the bright male hypothesis. Behav. Ecol. Sociobiol. 19:355-358.

BUCHER, G. E. 1959. Bacteria of grasshoppers of 
western Canada, III. Frequency of ocurrence, pathogenicity. J. Insect Pathol. 1:391-405.

CADE, W. H. 1981. Alternative male strategies: Genetic differences in crickets. Science 212:563-564.

Dingle, H. 1983. Behavior, genes and life histories: Complex adaptations in uncertain environments, pp. 169-194. In P. W. Price, C. N. Slobodchicoff, and W. S. Gaud (eds.), A New Ecology. Wiley, N.Y.

Dixon, K. S., AND W. H. CADE. 1986. Some factors influencing male-male aggression in the field cricket Gryllus integer (time of day, age, weight and sexual maturity). Anim. Behav. 34:340-346.

GRANT, B. R. 1985. Selection on bill characters in a population of Darwin's finches: Geospiza conirostris on Isla Genovesa, Galápagos. Evolution 39: 523-532.

Halliday, T. R. 1978. Sexual selection and mate choice, pp. 180-213. In J. R. Krebs and N. B. Davies (eds.), Behavioural Ecology. Sinauer, Sunderland, MA.

- 1983. The study of mate choice, pp. 3-32. In P. Bateson (ed.), Mate Choice. Cambridge Univ. Press, Cambridge, U.K.

Hamilton, W. D. 1982. Pathogens as causes of genetic diversity in their host populations, pp. 269296. In R. M. Anderson and R. M. May (eds.), Population Biology of Infectious Disease Agents. Springer-Verlag, Heidelberg, W. Ger.

Hamilton, W. D., and M. ZuK. 1982. Heritable true fitness and bright birds: A role for parasites? Science 218:384-387.

Houde, A. E. 1987. Mate choice based upon naturally occurring color-pattern variation in a guppy population. Evolution 41:1-10.

HowARD, R. D. 1978. The evolution of mating strategies in bullfrogs, Rana catesbiana. Evolution 32: 850-871.

Hyman, L. H. 1940. The Invertebrates: Protozoa through Ctenophora. McGraw-Hill, N.Y.

Kennedy, C. E. J., J. A. Endler, S. L. Poynton, AND H. McMins. 1987. Parasite load predicts mate choice in guppies. Behav. Ecol. Sociobiol. 21:291295.

Kudo, R. R. 1954. Protozoology, 4th Ed. Thomas, Springfield, IL.

Lande, R., AND S. J. Arnold. 1983. The measurement of selection on correlated characters. Evolution 37:1210-1226.

Lloyd, J. E., AND A. E. PACE. 1975. Seasonality in northern field crickets. Flor. Entomol. 58:31-32.

LOHER, W., AND B. ReNCE. 1978. The mating behavior of Teleogryllus commodus (Walker) and its central and peripheral control. Z. Tierpsychol. 46: 225-259.

ManNing, J. T. 1985. Choosy females and correlates of male age. J. Theoret. Biol. 116:349-354.

MCCauley, D. E., ANd M. J. Wade. 1978. Female choice and the mating structure of a natural population of the soldier beetle, Chauliognathus pennsylvanicus. Evolution 32:771-775.

Neville, A. C. 1967. Daily growth layers in animals and plants. Biol. Rev. 42:421-441.

Partridge, L. 1980. Mate choice increases a component of offspring fitness in fruit flies. Nature 283 : 290-291.

Price, T. D. 1984. Sexual selection on body size, territory and plumage variables in a population of Darwin's finches. Evolution 38:327-341.

Price, T. C., P. R. Grant, H. L. Gibbs, and P. T. BoAG. 1984. Recurrent patterns of natural selection in a population of Darwin's finches. Nature 309:787-789.

Read, A. F. 1987. Comparative evidence supports the Hamilton and Zuk hypothesis on parasites and sexual selection. Nature 327:68-70.

SakaluK, S. E., AND W. H. CAdE. 1980. Female mating frequency and progeny production in singly and doubly mated house and field crickets. Can. J. Zool. 58:404-411.

Simmons, L. W. 1986. Female choice in the field cricket Gryllus bimaculatus (De Geer). Anim. Behav. 34:1463-1470.

ThORNHILl, R. 1983. Cryptic female cohice and its implications in the scorpionfly Harpobittacus nigriceps. Amer. Natur. 122:765-788.

ThORNHILl, R., AND J. Alcock. 1983. The Evolution of Insect Mating systems. Harvard Univ. Press, Cambridge, MA.

WAtt, W. B., P. A. Carter, AND K. Donohue. 1986. Females' choice of "good genotypes" as mates is promoted by an insect mating system. Science 233 : 1187-1190.

WeATHERHEAD, P. J. 1984. Mate choice in avian polygyny: Why do females prefer older males? Amer. Natur. 123:873-875.

Zeigler, D. D., AND K. W. Stewart. 1985. Age effects on drumming behavior of Pteronarcella badia (Plecoptera) males. Entomol. News 96:157-160.

ZuK, M. 1987a. Variability in attractiveness of male field crickets (Orthoptera: Gryllidae) to females. Anim. Behav. 35:1240-1248.

- $1987 \mathrm{~b}$. The effects of gregarine parasites, body size, and time of day on spermatophore production and sexual selection in field crickets. Behav. Ecol. Sociobiol. 21:65-72.

- $1987 c$. The effects of gregarine parasites on longevity, weight loss, fecundity and developmental time in the field crickets Gryllus veletis and G. pennsylvanicus. Ecol. Entomol. 12:349-354.

1987d. Age determination of adult field crickets: Methodology and field applications. Can. J. Zool. 65:1564-1566.

Corresponding Editor: H. J. Brockmann 